\title{
Deforestation and Carbon Sequestration Research at Baima Snow Mountain Nature Reserve, Southwest China
}

\author{
Yunxi Zeng ${ }^{1, a}$ \\ ${ }^{I}$ The High School Affiliated to Renmin University of China, Beijing, China \\ ${ }^{a}$ Email: aimeezengyunxi@126.com
}

\begin{abstract}
The black snub-nosed monkey (Rhinopithecus bieti; also known as the Yunnan snub-nosed monkey) is an endangered animal mainly distributed in Baima Snow Mountain nature reserve, Southwest China. Given the poaching and habitat loss of Yunnan snub-nosed monkey, this study aims to investigate the current status of living environment of the Yunnan snub-nosed monkey from the perspective of deforestation and provide applicable solutions to maintain the local environmental sustainability. Based on GIS mapping, this study identifies three deforested areas in Baima Snow Mountain nature reserve's core zone. This study further assesses the economic and environmental benefits of reforestation in terms of the carbon market policy in China that promotes the development of forestry carbon trading. Specifically, the QGIS-LTR software is utilized to estimate the carbon sequestration value of these three areas with the data of carbon storage (mostly in cold temperate coniferous forest) and the biomass values. The carbon sequestration potential and the corresponding values of reforestation in these three deforested areas are estimated.
\end{abstract}

Keywords: Rhinopithecus bieti, Habitat fragmentation, Deforestation, Carbon market, Baima Snow Mountain nature reserve, Global warming

\section{INTRODUCTION}

Environmental issues such as global warming, air/water pollution, biodiversity loss, and deforestation, have presented major global threats for planet Earth. Human activities (e.g., use of fossil fuels, cattle ranching, and agriculture monocultures, etc.) contribute to increasing amount of greenhouse gases, thus intensifying the warming climate and related environmental issues [1].

China is the world's top emitter of greenhouse gases. Until 2019, China's carbon output accounted for more than a quarter of global emissions [2]. China's climate goals are to reach peak carbon emissions before 2030, net zero emissions by 2060, and have renewable energy sources make up 25 percent of the country's total energy consumption by 2030 [3]. On July 16, 2021, China announced the launch of its national carbon emissions trading market. This national carbon market policy facilitates global carbon sequestration by limiting companies' carbon emissions and encouraging carbon trading, which may lead to increased amount of forest restorations that can be evaluated as carbon credits in the carbon markets.
Previous studies reported that the potential habitat of Yunnan snub-nosed monkey, an endangered animal mainly distributed at Baima Snow Mountain nature reserve, Southwest China, decreased due to habitat fragmentations like deforestations caused by human activities (e.g., $[4,5])$. The interviews with residents indicate that Baima Snow Mountain nature reserve is exclusively funded by a tourism company; there are only 20 guards protecting the forest and the monkeys with salaries below average, contributing to potentially serious management issues of monkey protection.

The main objective of this study is to investigate the current status of living environment of the Yunnan snubnosed monkey and resolve this area's environmental and social issue to better protect the endangered Yunnan snub-nosed monkeys and maintain local sustainability. The creative part of this study is to detect deforested areas at Baima Snow Mountain nature reserve and assess the feasibility of reforestation in terms of China's new national carbon emissions trading market policy. This carbon trading requires accurate estimation of carbon sequestration potential, which can be estimated based on the biomass [6]. The calculation of biomass is essential 
for assessing the productivity and sustainability of the forest. Estimating forest biomass will enable the estimation of amount of $\mathrm{CO}_{2}$ that can be sequestered from the atmosphere by the forest.

\section{RESEARCH AREA}

The research area is Baima Snow Mountain Nature Reserve in Yunnan, Southwest China $\left(27^{\circ} 24^{\prime}-28^{\circ} 36^{\prime} \mathrm{E}\right.$, $98^{\circ} 57^{\prime}-99^{\circ} 25^{\prime} \mathrm{N}$ ), which has a vast territory with diverse and unique nature resources. The habitat of the Yunnan snub-nosed monkey is unusual that they live at high elevations in which snows are common and occur in firlarch-rhododendron forest with low diversity of tree species [7, 8]. They mainly distribute in evergreen needle-leaf forests, mixed needle-deciduous forest and evergreen broad-leaf forest.

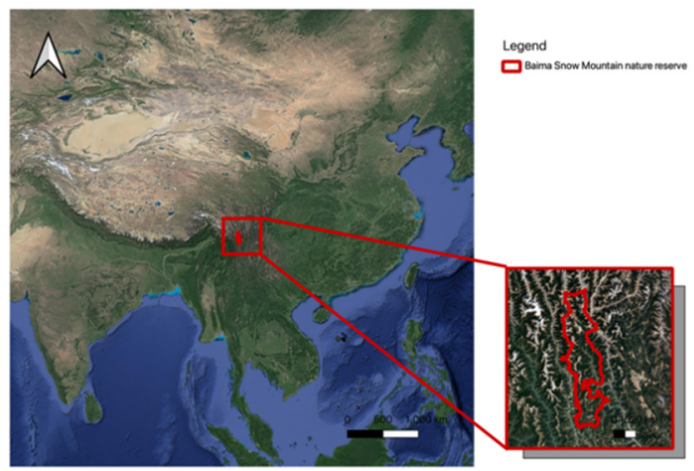

Figure 1 Baima Snow Mountain (Google Satellite 2021, OSM 2021).

\section{DATA AND METHOD}

This study used QGIS-LTR software (Version 3.16.8Hannover) to perform geographic mapping and analysis. To quantify the biomass and carbon sequestration of the area, this study applied GIS vectors in the research. The forest biomass map vector is downloaded from GLOBBIOMASS.org [9, 10] The Chinese carbon market data are obtained through China's Carbon emissions market website [11] to estimate the potential carbon market value.

\section{RESULTS AND DISCUSSTION}

\subsection{Deforestation}

Through several interviews with local villagers and monkey protection guards, it is found that there were many loggings and hunting activities during 1970s due to the economic destitute in Yunnan, Southwest China. People use tons of timber to trade for money to develop this place, leading to large amount of deforestation in this region, and thus threatening the living environment of Yunnan snub-nosed monkey. To protect the monkey, the local government has enacted protection policies and regulations to ban logging and hunting activities since 1998.

According to research [4], however, the Yunnan snub-nosed monkey has suffered from habitat fragmentation. Xia's research showed that the Yunnan snub-nosed monkey inhabits a predicted area of $7412.82 \mathrm{~km}^{2}$ between the Mekong River and Yangtze River (Fig. 2). Forest fragmentation has spatially blocked the monkey population communication and exchange. Xia divided the potential suitable habitat of the monkeys, which suggested the actual habitat area that the Yunnan snub-nosed monkey inhabited was only $4164.58 \mathrm{~km}^{2}$. And $1282.3 \mathrm{~km}^{2}$ had populations of the monkey in 1994 [7], but those groups may have disappeared (Fig. 2).

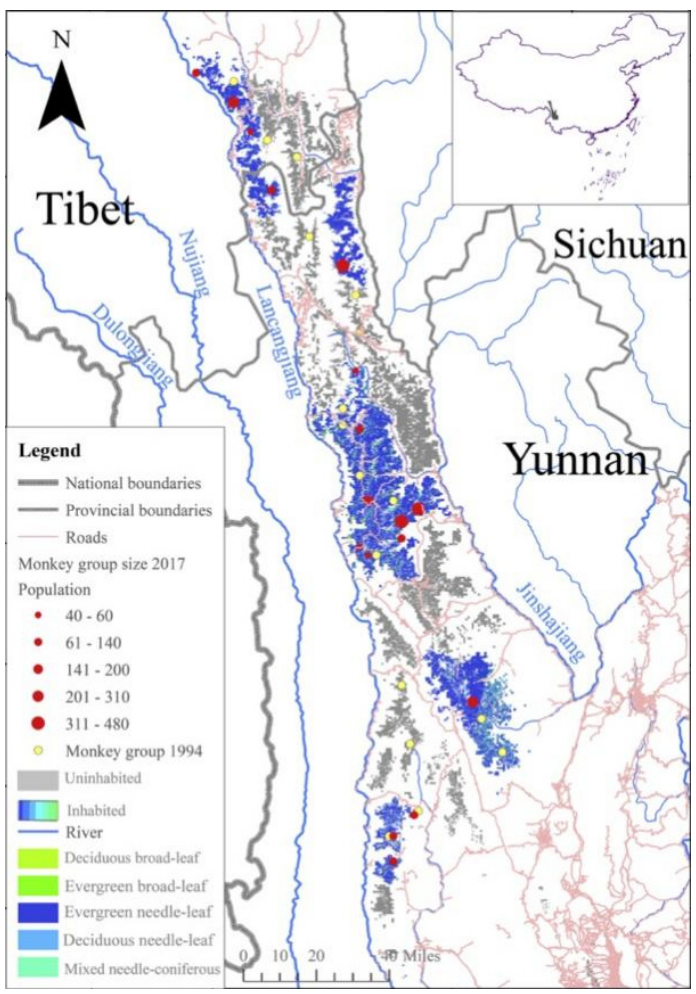

Figure 2 The potential suitable distribution area of $\mathrm{R}$. bieti (Modified from [4]).

Figure 3(a) shows the three zones in Baima Snow Mountain nature reserve: Core zone, Buffer zone and Experimental zone. The core zone corresponds to the most prioritized protect zone. Tourists are only allowed permission to the Experimental zone. By using GIS modeling to observe and evaluate the nature reserve, the result suggests that the core zone, the priority place needed to be preserved since 1998, has several deforested places. This study uses GIS mapping located three of these deforested places and calculated the surface areas. The surface area of these three places is $0.674 \mathrm{~km}^{2}$ (Fig. 3(b)). These three deforested places can be mainly due to natural logging before the ban regulation and did not recover after or illegal logging. 

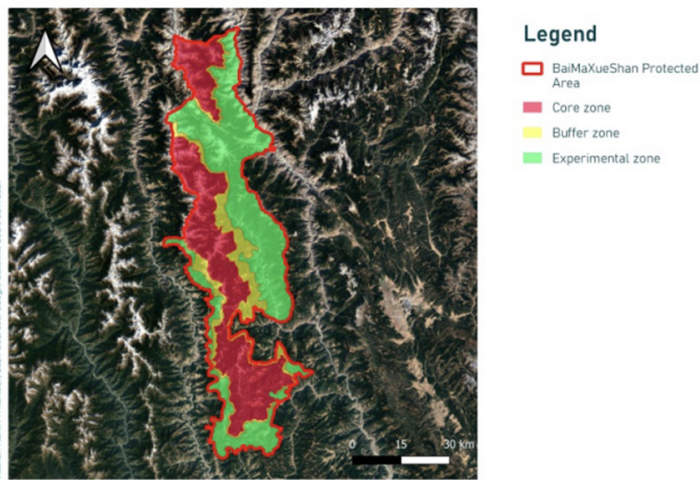

(a) Baima Snow Mountain Protection Zones
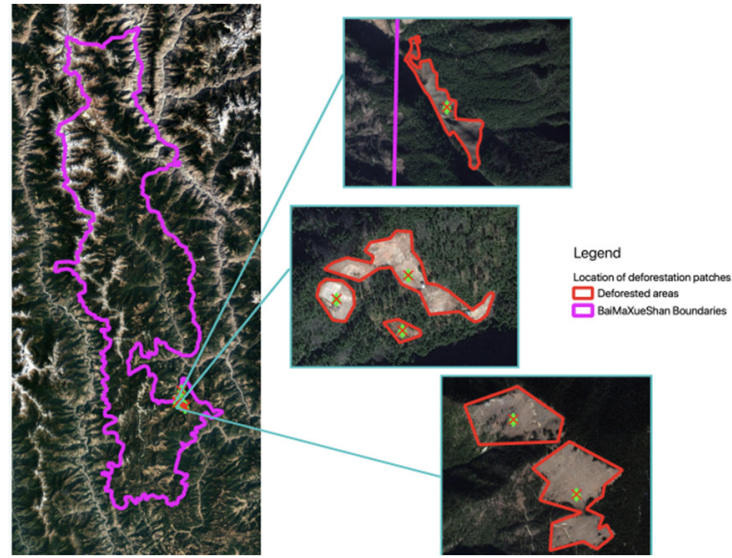

(b) The Potential Deforestation Areas in Baima Snow Mountain Nature Reserve

Figure 3 Deforestation Areas in Baima Snow Mountain Protection Zones

\subsection{Carbon market policy}

Carbon markets aim to decrease carbon emissions by offering financial rewards and punishments in the form of credits, allowances, or quotas that can be purchased and sold in a marketplace to companies. Under the carbon trading scheme, each company is allowed by the government to emit a certain amount of carbon dioxide emissions each year. If a specific company ends the year under its allotted limit, the extra carbon can be sold on the market as a credit. Conversely, if the company exceeds its limit, it is required to buy additional credits to compensate [12].

Carbon sequestration is a process of capturing carbon dioxide $\left(\mathrm{CO}_{2}\right)$ from the atmosphere and storage by forestland to reduce the accumulation of $\mathrm{CO}_{2}$ in the atmosphere. This process is essential to reduce the overheated of the earth that caused the climate change effects. The forest restoration can be evaluated as carbon credits to trade in the carbon markets. A carbon credit is a tradable permit or certificate that provides the holder of the credit the right to emit one ton of carbon dioxide or an equivalent of another greenhouse gas, and one carbon credit is equal to one ton of carbon dioxide emission [13]. By reforestation in the three defrosted areas, the local industry can obtain extra tons of carbon dioxide emissions every year, which can be traded in carbon market. According to a nonprofit survey quoted by the top Chinese business media outlet Caixin, carbon credits will likely be traded at around 50 yuan/ton, with a subsequent rise to 71 yuan/ton in 2025, and 93 yuan/ton by 2030 [14]. This study uses the average carbon market credit price in China: 50 yuan/ton.

Figure 4 shows the biomass at Baima snow mountain nature reserve, which can be used to calculate carbon sequestration for the three deforested areas identified by GIS mapping (Fig. 3b).

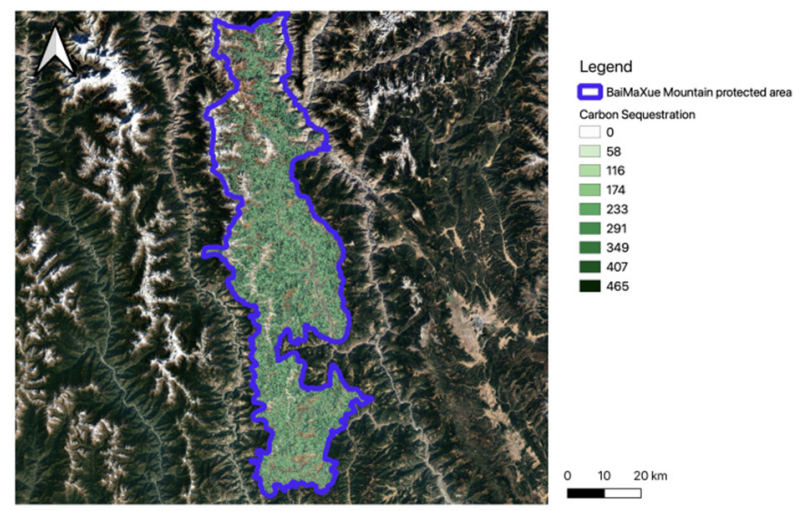

Figure 4 Baima Snow Mountain nature reserve biomass.

Different types of forests have different values of carbon storage.

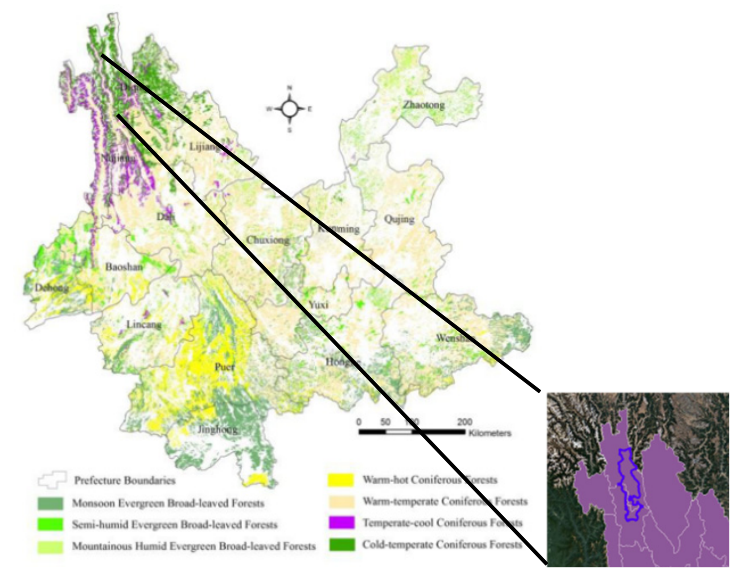

Figure 5 The distribution of forest vegetation in Yunnan Province in the 2010s (Modified from [15]).

The total current actual carbon storage of the seven types of forest vegetation in Yunnan Province was 871.14 $\mathrm{TgC}$, which the total actual carbon storage in coniferous forests was $489.88 \mathrm{TgC}$, accounting for $56.23 \%$ of the total. Warm-temperate Coniferous Forests (WTC) had a low mean biomass but a wide distribution, resulting in a high value of actual carbon storage. Warm-hot Coniferous Forests (WHC) and Cold-temperate Coniferous Forests (CTC) had intermediate levels of actual carbon storage, which were $137.78 \mathrm{TgC}$, and 122.98 TgC, respectively. In Baima Snow Mountain, 
there are mainly Cold-temperate Coniferous Forests that has a carbon storage of $122.98 \mathrm{TgC}$ (Fig.5) [15].

This study calculated the carbon sequestration potential by multiplying the biomass with cold temperate coniferous forests' carbon storage (122.98 TgC). The calculated carbon sequestration potential of cold temperate coniferous forests is $7099 \mathrm{Teq} / \mathrm{km}^{2}$, and the recognition period is 45 years. This study calculated the estimate profit of reforest cold-temperate coniferous forest on these three deforested areas. The multiplication of the carbon sequestration potential $\left(7099 \mathrm{Teq} / \mathrm{km}^{2}\right)$ and the surface area $0.674 \mathrm{~km}^{2}$ indicates a total of 4784.726 tons of carbon dioxide emission, which is then multiplied by the average carbon market credit price in China$50 y u a n /$ ton. The calculation result shows that the reforestation of these three areas can be exchanged for 239,244 yuan through the Chinese carbon trading market.

\section{CONCLUSION AND POTENTIAL IMPACT}

Based on the results and discussions presented above, the conclusions are obtained as below:

(1) To maintain local environmental sustainability and protect the endangered Yunnan snub-nosed monkeys, this study focuses on the deforestation in Baima Snow Mountain nature reserve and the feasibility of reforestation from the perspective of China's new carbon market policy.

(2) This study identifies three major deforested regions over the Baima Snow Mountain nature reserve based on GIS mapping, which can be due to natural logging before the ban regulation. The results suggest that the carbon sequestration of the three deforested areas in core zones is $7099 \mathrm{Teq} / \mathrm{km}^{2}$. Applying forest restoration methods can exchange for carbon credits and trade money of 239,244 yuan in Chinese carbon market.

(3) The results imply that Baima snow mountain nature reserve has several deforested areas particularly in the core zone. Many human activities are causing Yunnan snub-nosed monkey's habitat fragmentation. The local village are lack of fund to protect these monkeys sustainably. The applicable solution of reforestation and trade carbon sequestration potential as credits into the carbon market in China can economically benefit the Yunnan snub-nosed monkey protection in terms of improving their habitat's fragmentation and raising monkey protection guards' salary.

(4) The new carbon emissions trading market can be widely used in different areas in China, which potentially promote the development of forest restoration and environmental sustainability. Moreover, the reforestation can reduce the emissions of carbon dioxide and other greenhouse gases from industrial activities, which will mitigate potential environmental issues within the context of global warming.

\section{REFERENCES}

[1] IPCC, 2021: Summary for Policymakers. In: Climate Change 2021: The Physical Science Basis. Contribution of Working Group I to the Sixth Assessment Report of the Intergovernmental Panel on Climate Change [Masson-Delmotte, V., P. Zhai, A. Pirani, S. L. Connors, C. Péan, S. Berger, N. Caud, Y. Chen, L. Goldfarb, M. I. Gomis, M. Huang, K. Leitzell, E. Lonnoy, J.B.R. Matthews, T. K. Maycock, T. Waterfield, O. Yelekçi, R. Yu and B. Zhou (eds.)]. Cambridge University Press.

[2] Larsen, K., Pitt, H., Grant, M., \& Houser, T. (2021). China's Greenhouse Gas Emissions Exceeded the Developed World for the First Time in 2019. Rhodium Group. Accessed June 5, 2021.

[3] Albert, E., 2021. Introducing China's Carbon Market: What to know about Beijing's latest step to combat climate change.

[4] Xia, W., Zhang, C., Zhuang, H., Ren, B., Zhou, J., Shen, J., .. \& Li, D. (2020). The potential distribution and disappearing of Yunnan snub-nosed monkey: Influences of habitat fragmentation. Global Ecology and Conservation, 21, e00835

[5] Wong, M. H. G., Duan, C. Q., Long, Y. C., Luo, Y., \& Xie, G. Q. (2010). How will the distribution and size of subalpine Abies georgei forest respond to climate change? A study in Northwest Yunnan, China. Physical Geography, 31(4), 319-335.

[6] Vashum, K. T., \& Jayakumar, S. (2012). Methods to estimate above-ground biomass and carbon stock in natural forests-a review. Journal of Ecosystem \& Ecography, 2(4), 1-7.

[7] Long, Y., \& Kirkpatrick, C. R. (1994). Report on the distribution, population, and ecology of the Yunnan snub-nosed monkey (Rhinopithecus bieti). Primates, 35(2), 241-250.

[8] Long, Y., Kirkpatrick, R. C., Xiao, L., \& Zhong, T. (1998). Time Budgets of the Yunnan Snub-Nosed (Rhinopithecus [Rhinopithecus] bieti). In The natural history of the Doucs and Snub-nosed Monkeys (pp. 279-289).

[9] GLOBBIOMASS. org: Global Mapping. Retrieved from: https://globbiomass.org/wpcontent/uploads/GB_Maps/Globbiomass_global_da taset.html

[10] DeLamo, X., Ravilious, C. and Pollini, B. (2019) Using spatial information to support decisions on 
safeguards and multiple benefits for REDD + . Stepby-step tutorial v2.0: Understanding and comparing carbon datasets, using QGIS 2.18. Prepared on behalf of the UN-REDD Programme. UNEP World Conservation Monitoring Centre, Cambridge, UK.

[11] China's Carbon Emissions Market website. Retrieved from: http://www.tanpaifang.com/tanjiaoyi/

[12] Koty, C, A. (2021). China Briefing: China Launches Carbon Trading Market as Urgency to Cut Emissions Grows.

[13] Kiron, M. I., (2021). Textilelearner: Carbon Credit: Definition, Types and How Does It Works.

[14] Nakano, J., (2021). CSIS: China's New National Carbon Trading Market: Between Promise and Pessimism.

[15] Zhou, R., Li, W., Zhang, Y., Peng, M., Wang, C., Sha, L., ... \& Wang, S. (2018). Responses of the carbon storage and sequestration potential of forest vegetation to temperature increases in yunnan province, SW China. Forests, 9(5), 227. 